\title{
Future journals: paper or computers?
}

\section{STEPHEN LOCK}

Printed journals have been with us now for several hundred years and I believe that they will stay. Having said this, I believe that changes will be made, both in the format and in the method of producing journals. Nevertheless, by the end of this century the pattern of the $B M F$, for example, will still be recognisable to its first editors, Hennis Green and $R \mathrm{~J} \mathrm{~N}$ Streeten.

To take format first, in 1981 that of the $B M F$ underwent the first radical change in its 140 -year history. In effect, we added 16 pages every week but at the same time reduced the overall size of the journal. Let me explain this apparent paradox. With printing 94000 copies a week the $B M \mathcal{F}$ now has a circulation that is the third largest of a general medical journal in the world. We have also possibly the most varied circulation in the worldto doctors in university ivory towers and Third-World mission stations, in provincial general practice, and in large urban hospital complexes. One result of this disparity was that we could not satisfy all of our readers all the time.

Perhaps we should not try to attain this ideal, but we did wonder. whether we should not recognise that different groups had some widely different interests while at the same time all needed to keep in touch with a central core of knowledge and practice. Our solution was to introduce "split runs"- that is, to have a Clinical Research issue and a Practice Observed issue. In the Clinical Research issue there are eight (or occasionally four) pages of research papers without immediate clinical implications and in the Practice Observed issue there are eight (or four) pages primarily of interest only to family doctors. Because we think that it is important for all doctors to keep in touch with what is going on, each $B M Y$ is still complete, but in the Clinical Research issue the "Practice Observed" content is printed in miniprint, and, conversely, in the Practice Observed issue the "Clinical Research" section is in miniprint. We print the summaries of all research articles in ordinary size type, sell a cheap hand-lens to magnify this print if somebody wants to read it all, and offer libraries a special subscription rate for a complete set of pages in the normal size type. The savings come about because the advertisements are different in the two issues-for example, the Practice Observed issue does not contain any advertisements for hospital posts at all-and in this way we save about 26 million pages and at least $£ 300000$ in the costs of paper, printing, and postage every year.

The responses to this experiment were fairly mild: we had about 20 letters saying that it was the greatest innovation since the invention of the printing press and 20 letters saying that the whole thing was a swindle and that the status quo should be restored immediately.

The response to a bigger innovation the fournal introduced in 1981 was even more muted. This was the use of Prestel for part of the contents page of the fournal and for job advertisements. In this system data are called up on to the screen of the domestic television set via the ordinary telephone. Yet I believe that the use of Prestel is more significant for the whole future of publishing medical journals than the split run device. The latter is merely an adaptation of an old technology; the former is a radical new look at things-and I believe it is this that is

Partly based on a paper given at the celebrations for the 125th anniversary of the Nederlands Tijdschrift voor Geneeskunde in Amsterdam on 26 September 1981 and published in that journal $(1982 ; 126: 8-13)$.

British Medical Journal, London WC1H 9JR

STEPHEN LOCK, MA, FRCP, Editor going to play such a large part in producing journals in the future.

Much of this new technology is already with us, but at present both sides are rather like boxers in the first round of a lon contest-eyeing each other respectfully at a distance and nơ getting to grips at all. So may I move into the middle of the ring and make some prophecies.

\section{Computers in the editorial office}

It will not surprise you to learn that the central parts in m $\overrightarrow{\overrightarrow{g o}}$ scheme of the future will be played by the word processing system, transmission by telephone line, and the small deskto computer (figure). An article for publication will, I suggest, bie typed on a word processing system and transmitted by telephone line to the editorial office. Here it will be printed out by anothe computer and stored on a floppy disc, and at the same time will be registered on the journal files by the editor's secretary using the computer. Not only will this list the authors, numbers of pages, illustrations, and so on: it will also reject the article straight away if it does not conform with the house style-in other words, the right number of copies, references styled in the right way, and so on. If the article is all right then the office computer will go on to print a list of, say, six possible assessors to referee the article and a "profile" of these assessote -how long they took to reply about the last article; whethet? their reports were "good"-that is, they agreed with what the editor thought; whether they have any other work in hand fou the fournal (such as writing editorials or book reviews); an whether they have just started their annual holidays.

Such a programme is already working-for the Annals of Internal Medicine, for example-and we plan to introduce into the $B M \mathcal{F}$ office in the autumn. Once the editor has chose a referee the machine will produce addressed labels to put on the envelope in which the article is sent to him, not to mention the fact that every month or so it will automatically print reminder postcards if the referee has not returned the manuscript wit his comments. But I see any future developments going rather further. Recently, editors have become particularly worrie about two dishonest tendencies-dual publication and piract If a journal computer were to be linked, say, with a centra body-such as the Index Medicus-and the computers in other journals it could find out whether similar articles by the same authors had already been printed or accepted for publication. If? this way these problems could be solved, at least partially though there would be obvious questions of confidentiality an so on to be answered.

Once it had become apparent that any article was indee original, and a referee had been chosen, the editor could theff telephone the assessor to ask whether he would be willing to report on it. The assessor might want more details, in whice case the editor could transmit part of the article by telephone so that the referee could read this on his video display unit; oncef he had agreed to assess it the whole article would then be transmitted by land line, to be printed out by the referee's ow computer.

Similarly, the referee could transmit his report back to the editor's computer-and, again, the decision of the editoriat board could be conveyed to the author in this way. If the decision were to accept a revised article the author coula return his altered version back to the journal office, again usines the telephone line and the computer. For subediting, too, similar system could be used: in the journal office the subeditor 


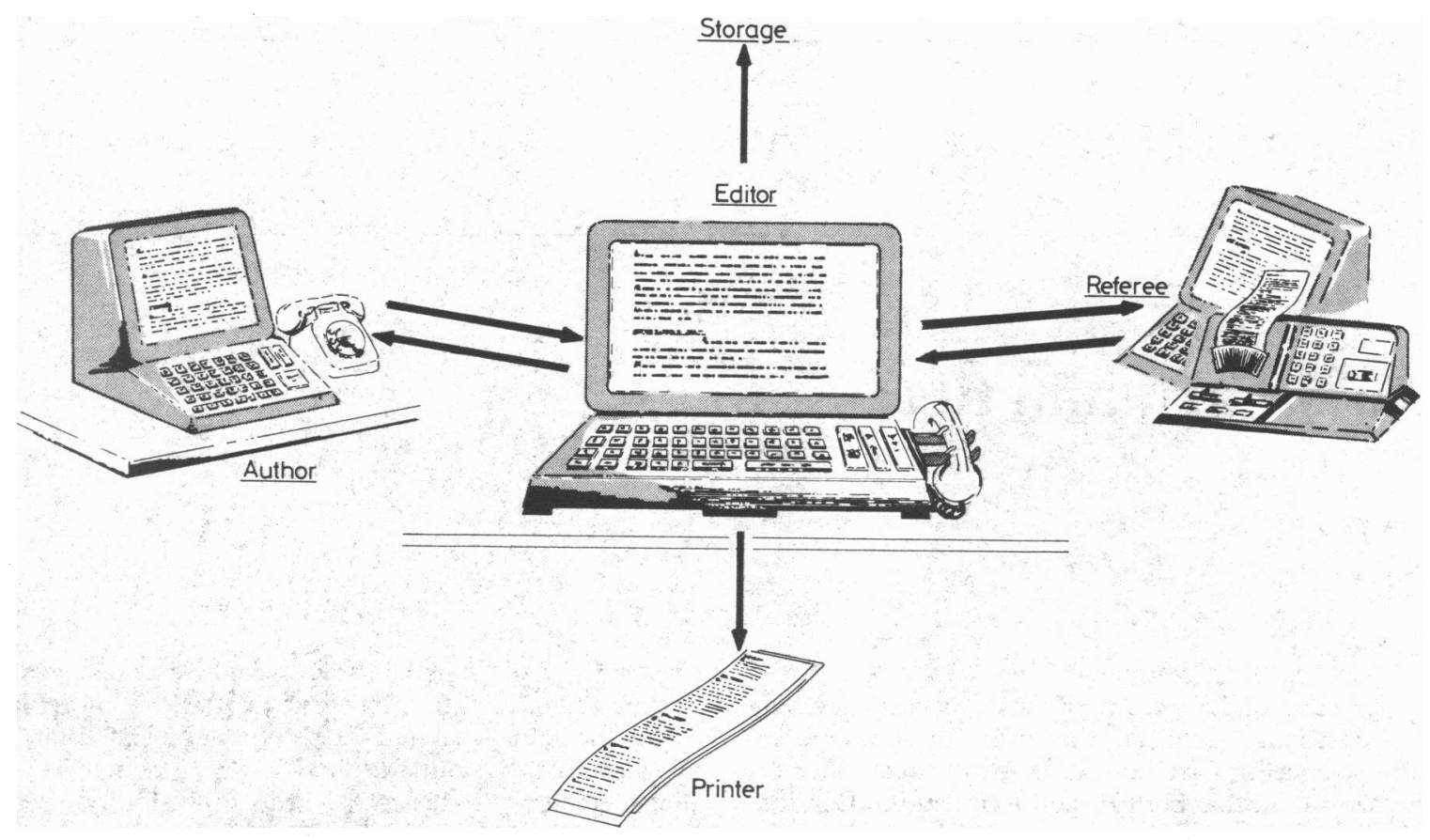

Communicating in the journal office of the future.

could go through the accepted manuscript and change it so that it conformed with the house style. He would then return the corrected paper to the author by telephone and word processor; and once he had approved, changed, and returned it to the journal office the whole article would be transmitted to the printer and, with the appropriate computer code, printed directly without further human intervention.

\section{Problems to be solved}

Things are not yet quite as easy as this, of course; and there are several minor problems that have to be solved. To begin with, it is expensive for detailed illustrations, such as half tones to be transmitted with any quality; next, "interfaces" are needed so that different systems can be linked with one another; the equipment must be installed in the offices of the authors as well as the editors; subediting on the video display unit takes up to three times as long as doing it manually; and the human problems that some printers will become redundant and lose their jobs need to be solved. Nevertheless, we are talking about the future and not 1982-though, as it happens, most of these systems have already been tried out and found to work. Again, the growth of the equipment has been phenomenal, and I think that within the next few years computers may become almost commonplace. After supper 10 years ago one was taken to play with the host's colour television and 20 years ago with his stereo hi-fi; in the last six months I have been shown word processors and storage units in ordinary homes as far afield as Sydney, Boston, and London, and, although all of them belonged to enthusiasts, I get the impression that cheap domestic versions are just around the corner.

Similarly, I cannot believe that solving technical difficulties will be all that hard: interfaces to link different types of equipment already exist, and I believe that printers are already planning to cope with the prospects of their jobs changing; one possible solution may be to give them posts as technical editors working in the journal office.

\section{Advantages}

Having said all this, I believe that this new system is not a pipe dream but will come about for several reasons. Firstly, and most importantly, it will enable journals to reach the readers in much the same format as they have today-that is, printed in the conventional way, on paper. Some people have suggested that in the distant future readers may choose which articles they want to read in a journal by looking at a table of contents on their television screen and then printing out only the selected articles on their own word processing system. This may be a possibility for the highly specialist journal, although the economic basis will have to be worked out, but I believe that for the general journal the subscriber will still want, and need, the whole copy. Any limited system, too, would lose the great advantage of "eavesreading"-noting articles in the complete journal that might be more relevant to the researcher's work. Nothing can rival the printed word for its convenience and for its permanence. You can read a journal when and where you like, as many times as you like, and store it for reference. Again, you can go over the authors' figures, reworking them and comparing them with your own.

Secondly, these changes will improve quality and probably reduce quantity. If, as seems possible, we eventually get agreement on a world style, most articles will conform to this when they are sent in to the journal office; if they do not an optical character reader attached to the office computer will recognise this and the article will automatically be returned to the author. This seemingly drastic method might eventually save a lot of money-in both the editorial office and the research units, where typists should no longer have to waste their time converting references in the Harvard style to those in the Vancouver system.

Thirdly, the search to see whether similar articles have been published or accepted for publication should eliminate much of the dual publication that goes on today.

Lastly, I believe that this system will enable authors to provide a lot more of their raw data. Every editor knows of the conflict that goes on between the space he can allow his authors to give their data and the needs of the rest of the journal. If many more data could be supplied to the editor and his referee for assessment and then not be printed but be stored in a central store which readers can call up for viewing on their own television set, this could do much to raise the standards of scientific accuracy and also eliminate another of today's horror storiesforgery of results. So I hope you will agree with me that these changes are inevitable, are something to look forward to rather than to be feared, and will raise the standards of journals to an even higher level. 